\title{
Evaluation of the Wind Potential and Optimal Design of a Wind Farm in the Arzew Industrial Zone in Western Algeria
}

\author{
Salah Mariha ${ }^{*}$, Leila Ghomrib, Benaissa Bekkouche ${ }^{\mathrm{b}}$ \\ aLaboratory developing physical-mechanical characterization and metallurgical materials, Abdelhamid Ibn Badis University, \\ Mostaganem, Algeria
}

${ }^{b}$ Signals and Systems Laboratory Research, Abdelhamid Ibn Badis University, Mostaganem, Algeria

\begin{abstract}
This work presents an assessment of the wind potential and a design methodology for a 10 MW wind farm in the Arzew industrial region, located in northwest Algeria, to improve the quality of service of the electricity grid and increase Algeria's participation in the use of renewable energy. The hourly wind data of 10 years (2005-2015) that correspond to the wind potential of the site were analyzed, such as: dominant wind directions, probability distribution, Weibull parameters, mean wind speed and power potential. The site has a mean annual wind speed of $4.46 \mathrm{~m} / \mathrm{s}$ at $10 \mathrm{~m}$ height, and enough space to locate the wind turbines. A comparative study was carried out between four wind turbine technologies to improve the site's efficiency and select the appropriate technology: PowerWind 56/ $900 \mathrm{~kW}$, Nordex N50/800 kW, Vestas V50/850 kW, NEG-Micon 44/750 kW. The estimate of the energy produced using WAsP software and the choice of the optimal architectural configuration for wind turbines installation was confirmed. A techno-economic and environmental study was carried out by HOMER software, to choose the model that produces the maximum annual net energy with a competitive cost in the global wind energy market, $\$ 0.068 / \mathrm{kWh}$, and that provides clean energy with a reduced emission of polluting gases. Finally, this work provides a good indicator for the construction of a wind farm in Arzew. O2020. CBIORE-IJRED. All rights reserved
\end{abstract}

Keywords: Wind resource assessment, Wind farm, Weibull distribution, Wind speed, Wind turbine, Power density, Optimization, WAsP, Arzew, Algeria.

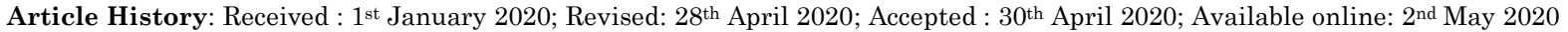

How to Cite This Article: Marih, S., Ghomri, L., and Bekkouche, B. (2020) Evaluation of the Wind Potential and Optimal Design of a Wind Farm in the Arzew Industrial Zone in Western Algeria. International Journal of Renewable Energy Development, 9(2), 177-187

https://doi.org/10.14710/ijred.9.2.177-187

\section{Introduction}

The increase in electricity consumption in recent years due to the development of industrial and domestic receivers is causing an accelerated increase in pollution (Ozturk \& Acaravci, 2010) (Halicioglu, 2009) (Ang, 2007). Therefore, the satisfactory solution for both sides of this equation (consumption and pollution) lies in the development of renewable energies (Edinger \& Kaul, 2000) (Zhang, 2007) (Reiche \& Bechberger, 2004) (Georgopoulou et al., 1998). The exploitation of these clean energies depends on the characteristics of the site's deposit. Algeria has a significant solar resource in the world (Stambouli, 2011). It represents the most important solar potential in the entire Mediterranean basin, i.e. 169,000 $\mathrm{TWh} /$ year for thermal solar energy, $13.9 \mathrm{TWh}$ /year for photovoltaic solar energy (Benabdelkarim \& Benatillah, 2016).

However, the difference in absorbed solar radiation causes temperature variations between regions, resulting in differences in air mass density and promoting air mass movement from one height to another. This phenomenon

*Corresponding author: salah.marih@gmail.com produces drafts between the low-pressure and highpressure areas, which generate the kinetic energy of the wind. The latter is a renewable energy source, which can be converted into electrical energy by wind turbine systems. Based on these data, Algeria created the first wind farm in the southwest (Adrar city) (Himri et al., 2020)(Mohamed et al., 2015), which has given good results for the exploitation of this technology to produce electricity in Algeria.

Based on these results, a major renewable energy project is underway to produce 22,000 MW of clean eclectic energy by 2030, of which 5,010 MW will be generated by wind energy. At the end of this national project, Algeria will reach $27 \%$ of the electricity produced from renewable sources (Programme national de développement des énergies renouvelables (2015 - 2030) - Portail Algérien des Energies Renouvelables, n.d.). Several studies have been carried out to determine the Algerian wind field ((Himri et al., 2010); (Boudia \& Guerri, 2015); (Abdeslame et al., 2017)).

This paper describes a simple approach to the continuity of the Algerian vision of wind energy development. It consists of assessing the wind potential and wind atlas of a site located near the city of Arzew, in northwest Algeria, as well as determining the optimal configuration and compatible wind turbine technology to improve the site's 
efficiency. This will make it easier for decision-makers. Estimating generation capacity and its relationship to installed equipment is a crucial step in the design process of a wind farm. An incorrect estimate of production can lead to significant economic losses.

An algorithm was developed to carry out this analysis, including the following steps:

$>$ Generality on the mathematical modelling of the frequency distribution of wind speed:

- Determination of the site's potential by WAsP software;

- Mapping the site.

> Technology and optimal configuration:

- Search for an adequate and cost-effective technology for the site;

- Comparison between two different configurations of turbine plantations.

$>$ Economic and environmental study of the different farms using Homer software.

\section{Mathematical modeling of wind speed frequency distribution}

It is important to express the frequency distribution of wind speed to assess the wind energy potential of a site. Modelling studies of the wind speed distribution have been oriented towards models combining power and wind speed. The usual models are as follows (OUSSAMA, 2015):

- Weibull distribution

- Weibull hybrid distribution

- Rayleigh distribution

\subsection{Weibull distribution}

The Weibull distribution (named after the Swedish physicist W. Weibull, who applied it to study the tensile strength of materials in 1930) has been used to represent wind speed distributions for application in wind load studies over a period of time and can give a good fit to experimental data (Lashin \& Shata, 2012). The Weibull distribution was used for the statistical study of ground data. The probability density and cumulative frequency of this distribution (Liu \& Yang, 2009) is given by:

$$
f(v)=\left(\frac{k}{A}\right)\left(\frac{v}{A}\right)^{k-1} \exp \left[-\left(\frac{v}{A}\right)^{k}\right]
$$

Where, $f(V)$ is the frequency distribution of the measured velocities; $\mathrm{k}$ is the Weibull form factor and it indicates the shape of the distribution and takes a value between 1 and 3

A small k-value means very variable winds, while constant winds give a higher $\mathrm{k}$-value; and $\mathrm{A}$ is the Weibull scale factor in $\mathrm{m} / \mathrm{s}$, a measure of the time series characterizing wind speed. A is proportional to the mean wind speed value and $\mathrm{A}>0$. The probability density and cumulative frequency of this distribution is given by (Emeksiz \& Cetin, 2019)(Al Zohbi et al., 2015):

$$
F(v)=\int_{-\infty}^{v} f(v) \cdot d v=1-\exp \left[-\left(\frac{v}{A}\right)^{k}\right]
$$

The probability function of Weibull reveals that high mean wind speeds rarely occur while moderate winds are more frequent. Thus, the Weibull distribution can facilitate many of the calculations required by wind data analysis.

\subsection{Weibull hybrid distribution}

The Weibull hybrid distribution is used when the frequency of calm winds recorded at a given site is greater than or equal to $15 \%$. Indeed, this proportion cannot be neglected and must be taken into account when characterizing a site from a wind perspective (Al Zohbi et al., 2015). This distribution is expressed as:

$$
f(v)=\left(1-f_{O}\right)=\left(\frac{k}{A}\right)\left(\frac{v}{A}\right)^{k-1} \exp \left[-\left(\frac{v}{A}\right)^{k}\right]
$$

for $\quad v>0$

$$
f(v)=\left(f_{O}\right) \quad \text { for } \quad v=0
$$

Where, $\mathrm{ff}_{0}$ is the frequency of calm winds

\subsection{Rayleigh distribution}

The Rayleigh distribution is a special case of the Weibull distribution for the case where the form factor $\mathrm{k}$ is equal to 2 ; its probability density is given by:

$$
F(v)=\int_{-\infty}^{v} f(v) \cdot d v=2\left(\frac{v}{A^{2}}\right) \exp \left[-\left(\frac{v}{A}\right)^{2}\right]
$$

In this study the wind energy potential was evaluated by the Weibull distribution which is the most used in this field and its parameters were determined.

\subsection{Determination of Weibull parameters}

The characteristics of the wind will determine the amount of energy that can actually be extracted from the wind field. Measurements of wind speed and direction over a long period of time are required (one to ten years) to establish the properties of a site.

However, previous studies in the field of wind energy have shown that the most important feature is the statistical distribution of Weibull. It has proved to be the most suitable in the field of wind energy. Usually, the form factor characterizes the symmetry of the distribution. Two methods were used to determine the two Weibull parameters $\mathrm{K}$ and $\mathrm{A}$ for sites in the region.

\subsubsection{Wind variability method (empirical method)}

This empirical approach consists in estimating $\mathrm{k}$, based on wind variability and mean wind speed (Al Zohbi et al., 2015).

$\mathrm{K}=1.05 \mathrm{~V}^{0.5}$ for low wind variability $(\mathrm{V}<3)$

$\mathrm{K}=0.94 \mathrm{~V}^{0.5}$ for mean wind variability $(3<\mathrm{V}<4)$

$\mathrm{K}=0.83 \mathrm{~V}^{0.5}$ for high wind variability $(\mathrm{V}>4)$

The calculation of 'A' is based on the following formula:

$$
v_{m}=A \cdot \Gamma\left(1+\frac{1}{k}\right)
$$

where, $\Gamma$ is the gamma function defined by $\Gamma(v)=\int_{0}^{\infty}\left(t^{x-1}\right) \cdot e^{t-1} d t$

The gamma function is based on the following equations:

$$
\Gamma(\mathrm{e}+1)=\mathrm{e} \Gamma(\mathrm{e}), \quad \forall \mathrm{e} \in \mathrm{R}, \quad \Gamma(\mathrm{n}+1)=\mathrm{n} !, \quad \forall
$$$$
\mathrm{n} \in \mathrm{N}, \Gamma(0,5)=\sqrt{\pi}
$$ 
The gamma function is a direct generalization of the notion of factorial for integer real numbers.

\subsection{2. $\quad$ Standard deviation method}

If the mean speed and standard deviation are available, the estimation of the parameters is calculated using the following two equations(Khalid Saeed et al., 2019):

$$
\begin{aligned}
& k=\left(\frac{\sigma}{V}\right)^{-1.086} \\
& A=\left(\frac{V}{\Gamma\left(1+\frac{1}{k}\right)}\right)
\end{aligned}
$$

where, $\sigma$ is the standard deviation of the mean wind speed.

\subsection{Vertical extrapolation of mean wind speed}

In general, wind speed measurements are made at an altitude of $10 \mathrm{~m}$ above the earth's surface. However, it is necessary to estimate wind speed at different altitudes, as it increases with altitude. The extrapolation of wind speed for different altitudes is obtained as follows (Al Zohbi et al., 2015):

$$
\frac{V}{V_{0}}=\left(\frac{Z}{z_{0}}\right)^{\alpha}, \alpha=\frac{1}{\ln \left(\frac{Z g}{r_{0}}\right)}
$$

where, $\mathrm{V}_{0}$, is the wind speed and is measured at $10 \mathrm{~m}$ altitude (the speed is calculated at altitude $\mathrm{Z}$ ); $\alpha$ is the power law exponent which is a function of surface roughness; $\mathrm{Zg}$ is the geometric mean height $\left(\mathrm{Z}_{0} * \mathrm{Z}\right)^{0.5}$ and $\mathrm{r}_{0}$ is the ground roughness (Al Zohbi et al., 2015).

Table 1.

Roughness of different surfaces (Wright, 2010)

\begin{tabular}{cc}
\hline Surface type & Roughness \\
\hline Sand & 0.10 \\
Mowed grass & 0.13 \\
Tall grass & 0.19 \\
Suburb & 0.32 \\
\hline
\end{tabular}

\subsection{Evaluation of the mean wind power density}

The power density of wind energy is the most important characteristic of the wind. It represents the amount of energy produced by the wind. For example, assuming that there is a cross-section through which the wind blows perpendicularly (Quan \& Leephakpreeda, 2015), the wind energy is given by the following equation:

$$
P=\frac{1}{2} \rho S v^{3}
$$

where, $\rho$ is the density of the air which depends on pressure (altitude), temperature and humidity. It is assumed to be constant since its variation does not significantly affect the wind resource calculation.

In this study, the mean air density for each site is used according to its altitude. The distribution density of wind energy gives the distribution of wind energy at different wind speeds. It is obtained by multiplying the wind power density by the probability of each wind speed as follows:

$$
\frac{P(v)}{s} f(v, k, A)=\frac{1}{2} \rho v^{3} f(v, k, A) \quad W / m^{3} s
$$

Using equation (12) during a study period, both parameters $\mathrm{A}$ and $\mathrm{k}$ can be used to estimate monthly or annually the wind power density per unit area by this expression (Emeksiz \& Demirci, 2019):

$$
P(v)=\frac{1}{2} \rho A^{3} \Gamma\left(1+\frac{3}{k}\right)
$$

In addition, the extrapolation of the mean power for a height less than $100 \mathrm{~m}$, the wind power density above ground level is given as follows:

$$
P_{Z}=P_{10}=\left(\frac{Z}{10}\right)^{3 \alpha}, \alpha=\frac{1}{\ln \left(\frac{z_{g}}{r_{0}}\right)}, \text { pour } \mathrm{Z}_{0}=10 \mathrm{~m}
$$

\subsection{Wind energy estimation}

From the wind measurements, it is possible to calculate the wind energy available at a given location. In practice, the annual wind energy, expressed in $\mathrm{kWh} / \mathrm{m}^{2}$, is calculated using the Betz limit as follows:

$$
E_{B}\left(\frac{\frac{k w h}{m^{2}}}{a n}\right)=3.56 \sum f_{i} v_{i}^{3}
$$

where, $\mathrm{f}$ is the frequency corresponding to the wind speed $\mathrm{V}$, center of class $i$.

This calculation can be performed using the Weibull distribution, obtaining the following equation (Keyhani et al., 2010):

$$
\frac{E}{S}=\frac{1}{2} \rho A^{3} \Gamma\left(1+\frac{3}{k}\right) \cdot T
$$

\section{Determination of site potential using wasp software}

\subsection{Calculation methodology}

WAsP ("Wind Energy Industry-Standard Software WAsP".2017) software was used during this study to simulate the site parameters, with a database of wind parameters collected over a 10-year period by the metrology station in the Arzew region. Wind speed and direction at a height of $10 \mathrm{~m}$ from the ground were collected between 01/01/2005 and 31/12/2015 for three hours per day. These data were used to assess wind power and energy potential, by assessing monthly and seasonal variations in mean wind speed and its vertical profile.

\subsection{WAsP software overview ("Wind Energy Industry- Standard Software - WAsP”.2017)}

WAsP is a software program for wind condition prediction, wind resource prediction and wind energy production. It allows the analysis of all series of wind direction and wind speed measurements. A Weibull distribution function is smoothed at the estimated frequencies to provide scale and shape parameters for each sector. The software takes into account the effect of different surface conditions, losses by wake effects due to structures and other obstacles, and wind modification imposed by specific variations in surface height around the wind measurement mast in question. Over the years, WAsP has become one of the industry standards for extrapolating wind resources. This model is currently used in more than 110 countries around the world. 


\section{Results of site potential assessment and discussion}

The dominant wind directions and wind speed frequencies were determined to identify and assess the potential of the Arzew site. The amplitude and stability of the mean wind speed were also studied.

\subsection{Determination of dominant wind directions}

A seasonal and an annual study of all wind directions were conducted using WAsP software over a 10 -year period to determine the dominant wind directions. A seasonal study was chosen to identify changes between seasons and define the best wind field for this coastal site. The WAsP simulation allowed to represent the wind roses for each season as shown in Figure 1.
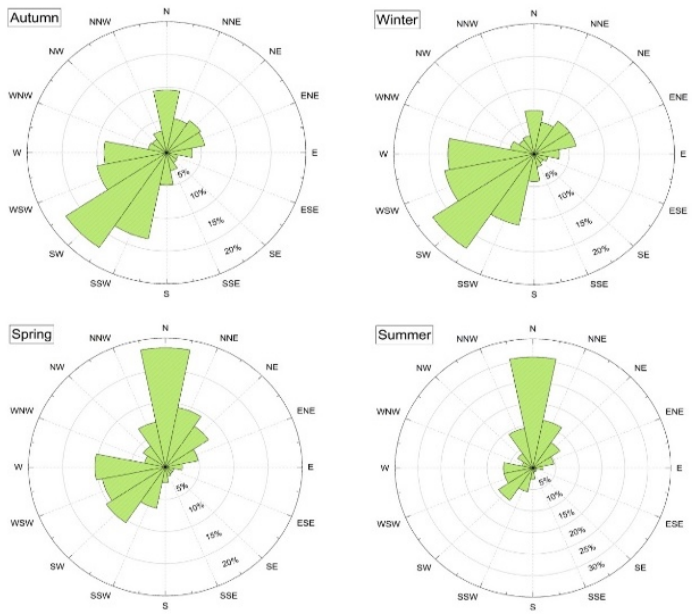

Fig. 1 Seasonal resource analysis at a height of $10 \mathrm{~m}$ (wind rose)

Based on the analysis of wind roses for each season according to prevailing winds, it can be observed that the prevailing southwest (S-W) winds in winter and autumn can reach $17 \%$. While spring and summer have high frequencies on the north side, which could be interpreted by marine currents at $18 \%$ and $25 \%$ respectively. From this seasonal analysis it can be concluded that there are two dominant directions of the wind for the Arzew site: southwest (S-W) and north (N).

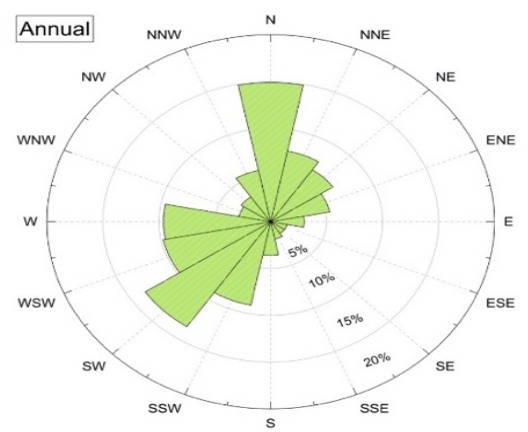

Fig.2 Annual resource analysis at a height of $10 \mathrm{~m}$ (wind rose)

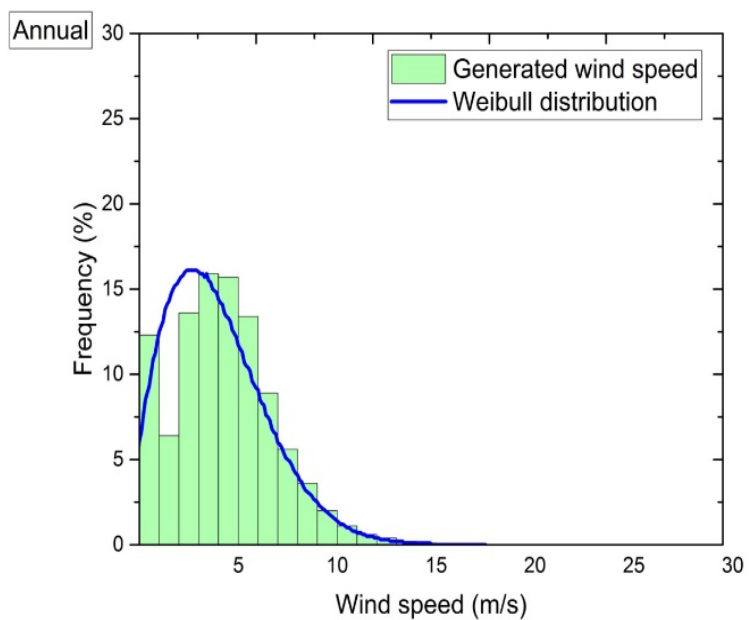

Fig.3 Annual resource analysis at a height of $10 \mathrm{~m}$ (wind speed histogram fitted by Weibull distribution)

Therefore, according to the annual analysis, two dominant directions were recorded, $15 \%$ of the north wind and $13 \%$ of the southwest wind (S-W) as shown in Figure 2. The annual analysis confirmed the result of the seasonal analysis. These results allow to choose the direction in which the wind turbines are installed within the site to obtain the best possible performance.

\subsection{Determination of wind speed frequencies}

Following the determination of the dominant wind directions, the variation in wind speed was studied using Weibull histograms. Figures 3 and 4 show Weibull distribution graphs, and seasonal and annual wind frequency histograms.

Figure 3 shows that autumn has maximum frequencies that exceed $15 \%$ for a speed of $4 \mathrm{~m} / \mathrm{s}$ to $6 \mathrm{~m} / \mathrm{s}$ with a wind speed variation range of up to $15 \mathrm{~m} / \mathrm{s}$. While winter has a wide maximum frequency range with stability for speed values between $3 \mathrm{~m} / \mathrm{s}$ and $6 \mathrm{~m} / \mathrm{s}$, and wind speed variation can reach $18 \mathrm{~m} / \mathrm{s}$. Spring has almost the same characteristics as the autumn season. In general, summer is the least windy period, but as far as the location of Arzew is concerned, the region studied is characterized by the phenomenon of marine currents, which offer stable winds of $15 \%$ in a wide range from $3 \mathrm{~m} / \mathrm{s}$ to $6 \mathrm{~m} / \mathrm{s}$, with a maximum seasonal velocity of $14 \mathrm{~m} / \mathrm{s}$.

The annual study presented in Figure 4 shows the same results observed in all seasonal distributions, particularly between $3 \mathrm{~m} / \mathrm{s}$ and $6 \mathrm{~m} / \mathrm{s}$. Based on the interpretation of the seasonal and annual results from the Arzew site, it can be noted that seasonal data are stable and high frequencies are present at speeds between $3 \mathrm{~m} / \mathrm{s}$ and $6 \mathrm{~m} / \mathrm{s}$. These results are a good indicator of the wind potential in this region. 

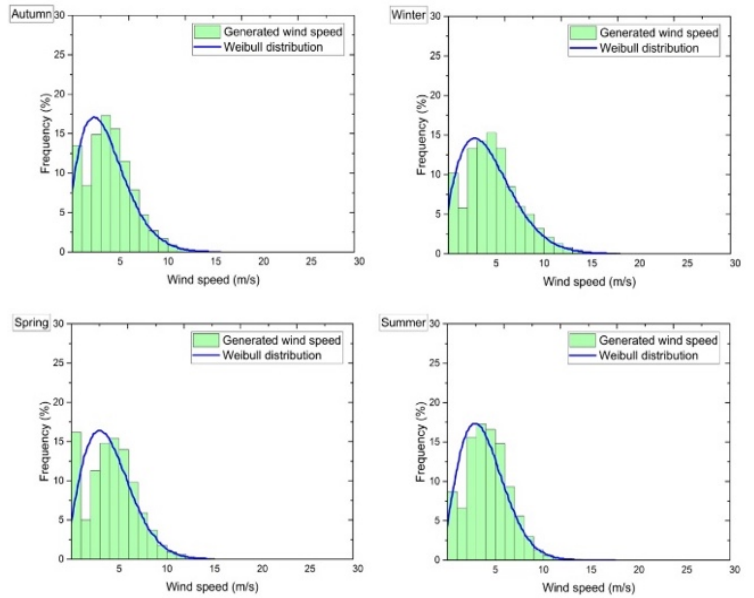

Fig.4 Seasonal resource analysis at a height of $10 \mathrm{~m}$ (wind speed frequency with fitted Weibull distribution)

\subsection{Study of the stability amplitude of the mean wind speed}

The assessment of the wind potential of each study site is based on two main characteristics: the amplitude of the mean wind speed and its stability. The temporal variation in wind speed with the mean shape variation of the Weibull $\mathrm{k}$ parameter is illustrated in Figures 5, 6 and 7 for the annual, monthly and daily changes, respectively.

Based on the 10-year presentation (Figure 5), it can be observed that the variation in wind speed per year is between $3.9 \mathrm{~m} / \mathrm{s}$ and $4.79 \mathrm{~m} / \mathrm{s}$; this represents a variation of $18 \%$. This variation shows that the Arzew region provides high wind speeds for wind exploitation.

The studied area has a mean wind speed of $4.46 \mathrm{~m} / \mathrm{s}$. This value is very acceptable in comparison with other studies in the northern Algerian's arid like the region of Ksar-Chellala which has a mean wind speed of $3.94 \mathrm{~m} / \mathrm{s}$ (Louassa et al., 2017). The annual mean wind speed value of the six stations (Oran, Setif, Skikda, Tlemcen, Tiaret, and Miliana) was resp.: 4.20, 3.46, 3.18, 2.64, 5.07, and $2.91 \mathrm{~m} / \mathrm{s}$ at $10 \mathrm{~m}$ (Belabes et al., 2015).

The lowest yearly mean wind speed is found to be equal to $1.98 \mathrm{~m} / \mathrm{s}$ in Bejaia site in the coastal region.(Saheb Koussa et al., 2016), Tiaret $5.58 \mathrm{~m} / \mathrm{s}$ Djelfa $3.88 \mathrm{~m} / \mathrm{s} \mathrm{El}$ bayedh $4.73 \mathrm{~m} / \mathrm{s}$ (Merzouk \& Merzouk, 2012). This comparison show that we have a promising wind speed value for installation of wind farm. For wind stability, the $\mathrm{k}$ parameter varies from 1.38 to 2.12 . These values indicate that wind has a mean and variable stability from one year to another.

The values recorded in other studies in the region of the north of the country, The shape factor is between 1.5 and 1.24 in the region of Ksar-Chellala (Louassa et al., 2017). And the shape factor is $1.44,1.47,1.40,1.48,1.48,1.12$ in the regions of Milaina, Oran, Setif , Skikda, Tiaret, Tlemcen respectively,(Belabes et al., 2015) and 1.71, 1.62 in Djelfa and El bayadh(Merzouk \& Merzouk, 2012). We assume that shape factor value in our studied area validate our choice.

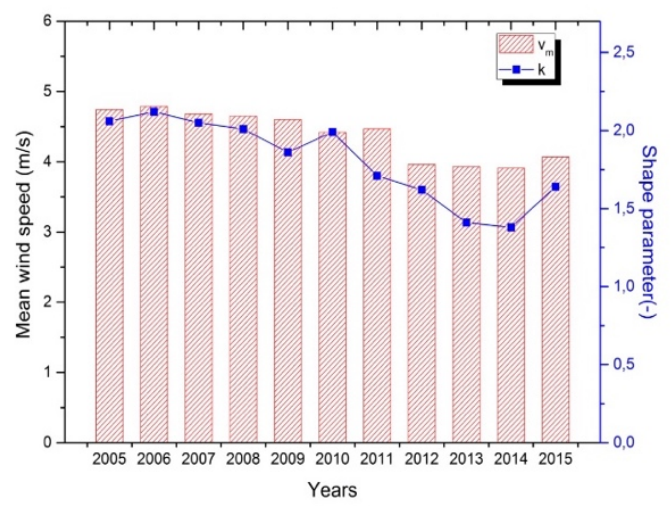

Fig.5 Annual variation of mean wind speed and shape Weibull parameter at a height of $10 \mathrm{~m}$

The monthly presentation (Figure 6) indicates that wind speed has a high value between January and May. However, the wind profile is more stable in the other months of the year, as mean wind speeds are always higher than $3.87 \mathrm{~m} / \mathrm{s}$. The $\mathrm{k}$ parameter varies between 1.59 and 1.9 ; this variation shows that the wind becomes more stable and gives values approximated from one month to another.

The presentation of one day per three-hour class (Figure 7) shows that the windiest periods are from 12:00 to 18:00. In the morning, the wind speed varies between $4.73 \mathrm{~m} / \mathrm{s}$ and $5.59 \mathrm{~m} / \mathrm{s}$, a mean wind speed greater than 4 $\mathrm{m} / \mathrm{s}$ is recorded throughout the day. The Weibull $\mathrm{k}$ parameter varies between a minimum value of 1.51 to $6 \mathrm{H}$ and a maximum value of 2.22 to $15 \mathrm{H}$. However, all curves have a similar wind speed trend for the Weibull distribution.

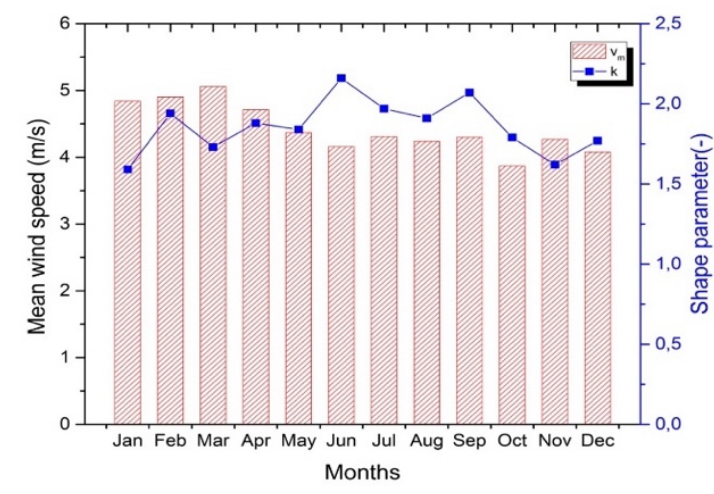

Fig.6 Monthly variation of mean wind speed and shape Weibull parameter at a height of $10 \mathrm{~m}$

Figure 8 shows the annual variation in the estimated power density of the study site. The power density varies during the study period (January 2005 - December 2015) between $100 \mathrm{~W} / \mathrm{m}^{2}$ and $132 \mathrm{~W} / \mathrm{m}^{2}$. It is noteworthy that the minimum power density values are recorded for the years 2006 and 2012, while the maximum value was recorded in 2005 . 


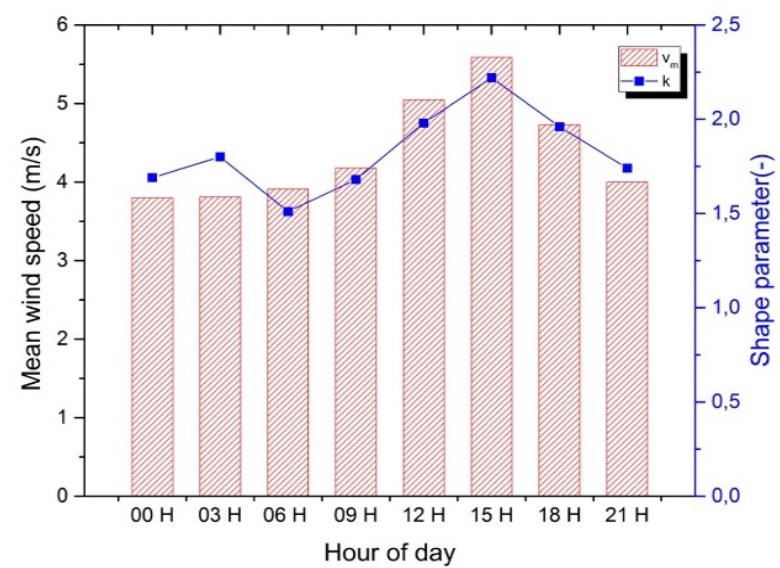

Fig.7 Mean annual diurnal profile of wind speed and shape Weibull parameter at a height of $10 \mathrm{~m}$

Compared to other studies, the mean power density rated $152 \mathrm{~W} / \mathrm{m}^{2}$ in the region of Ksar-Chellala (Louassa et al., 2017) and $51,127,80,55,238,51 \mathrm{~W} / \mathrm{m}^{2}$, in the regions of Milaina, Oran, Setif, Skikda, Tiaret, Tlemcen respectively(Belabes et al., 2015), and 81.57, $157.49 \mathrm{~W} / \mathrm{m}^{2}$ in Djelfa and El bayadh(Merzouk \& Merzouk, 2012).

In conclusion, Arzew always keeps good values regarding power density. It can be concluded that there is no period in the study site where the wind speed does not exceed $4 \mathrm{~m} / \mathrm{s}$. This speed value is promising for wind installations; therefore, the studied site has a significant and stable wind deposit.

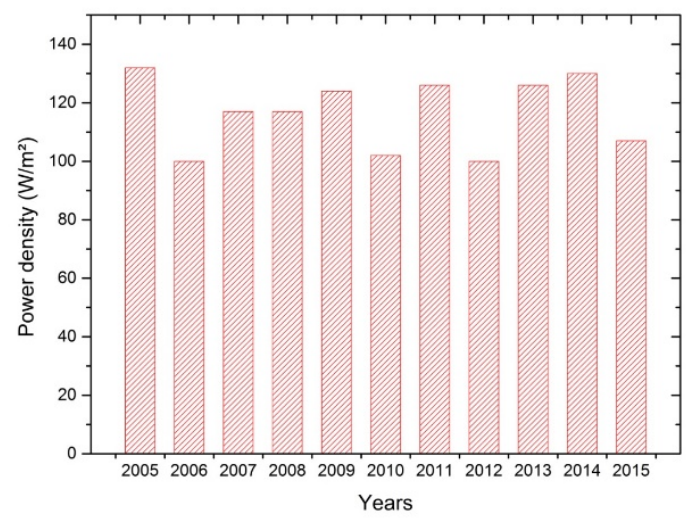

Fig.8 Annual variation of power density

\section{Cartography}

A wind atlas of the site was drawn to represent the wind field of the study site. First, the roughness areas were delimited (Figure 9), then classified by type (Table 1). NASA SRTM mapping data and statistical analysis of recorded wind data ("Home Page | Earth Resources Observation and Science (EROS) Center".2017) were used with WAsP software ("Wind Energy Industry-Standard Software - WAsP'.2017 ). The wind atlas for the entire Arzew region was drawn up at an altitude of $10 \mathrm{~m}$ (Figure 10 ), which is the preferred reference for the location of the wind turbines studied.

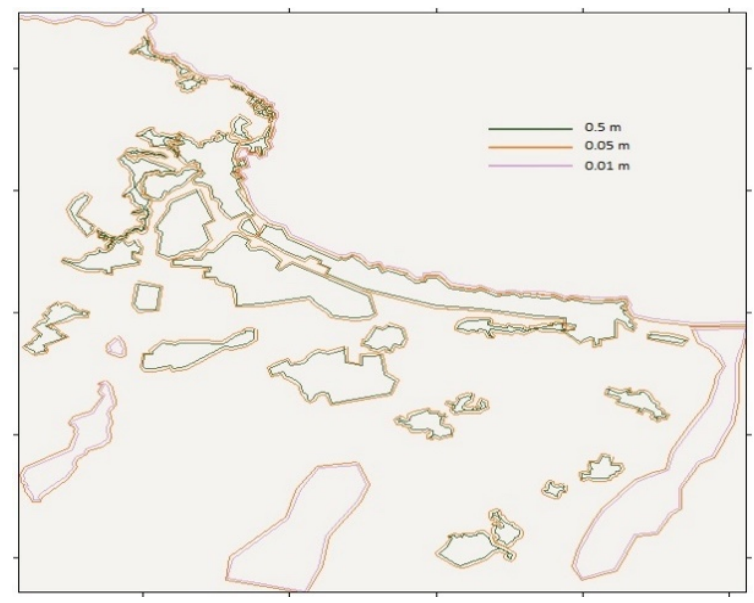

Fig.9 Roughness lengths map of the studied area

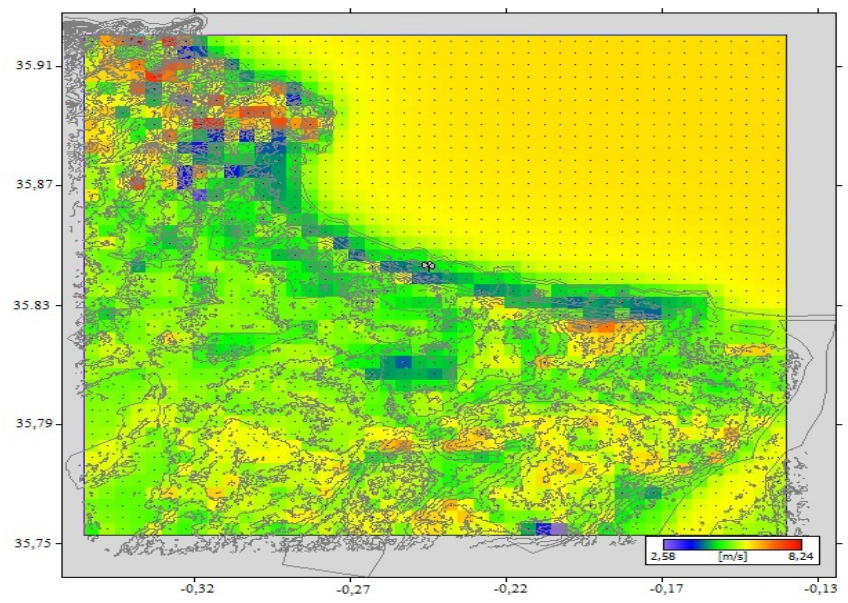

Fig .10 Wind speed at the studied area at height of $10 \mathrm{~m}$

\section{Technology selection and optimal configuration}

Based on the good results obtained on the wind potential of the site through statistical analysis of the databases and calculation of the probability density rate by Weibull function, the second part of the sizing process, which consists in finding the optimal installation and choosing the appropriate technology, is completed.

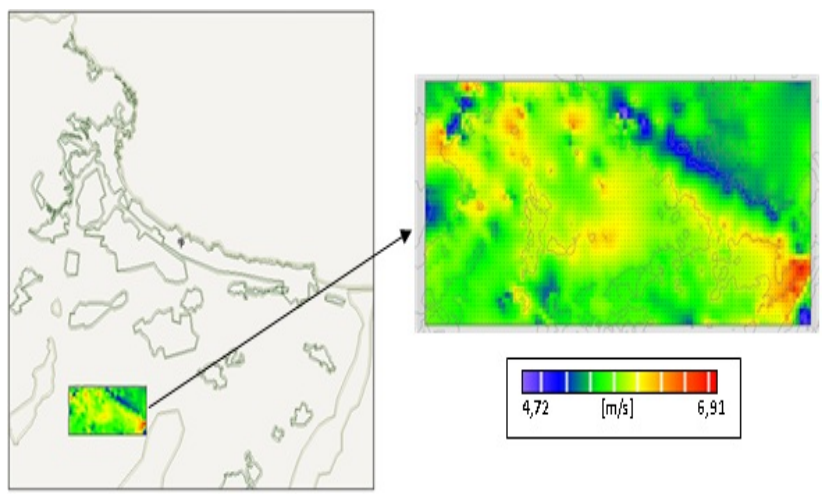

Fig.11 Wind speed at the selected site for wind farm simulation at $10 \mathrm{~m}$ height 
Figure 11 shows the site chosen for the installation of the wind turbines. It can be noticed that a large part of the area is affected by a wind speed range between 4.7 and 6.9 $\mathrm{m} / \mathrm{s}$. This analysis provides a good pressure gauge for the installation of a wind farm on this site.

\subsection{Adequate and cost-effective technology for the site}

For the installation of the wind turbines, four of the most commonly used models are used. They are characterized by a nominal capacity of 750 to $900 \mathrm{~kW}$ and a hub height of 50 to $59 \mathrm{~m}$ as shown in Table 2 . Figure 12 shows their characteristics in terms of power produced as a function of speed.

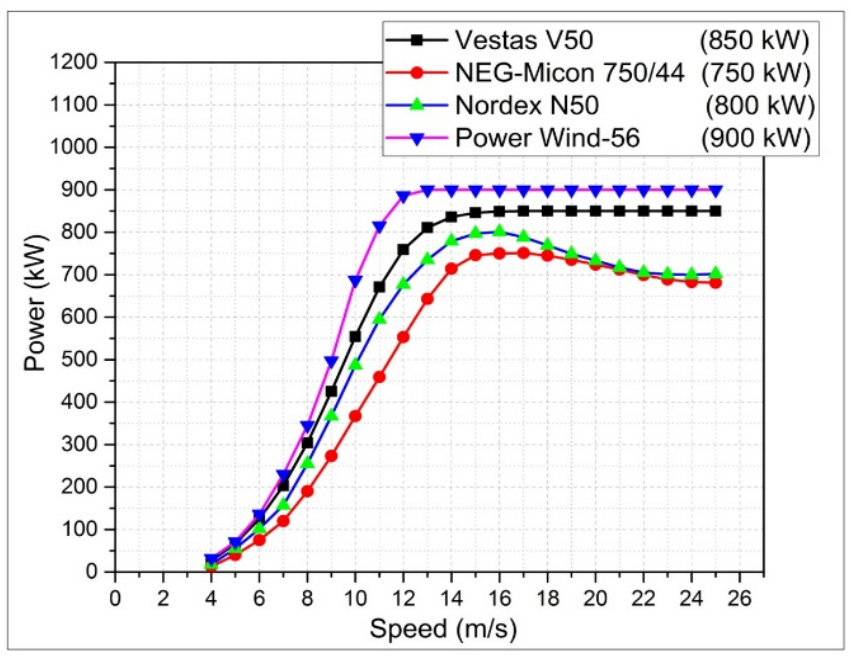

Fig.12 Power curve of wind turbines

\subsection{Comparison between two different turbine layout configurations}

\subsubsection{Wind farm simulation}

The following provisions were used to ensure the production of the nominal power of $10 \mathrm{MW}$ :

- Wind farm of 12 Vestas V52 wind turbines for a total power of 10.2 MW;

- Wind farm of 13 NEG-Micon750 / 44 wind turbines with a capacity of $10.4 \mathrm{MW}$;

- Wind farm of 12 NordexN50 wind turbines with a capacity of $10.6 \mathrm{MW}$

- Wind farm of 14 PowerWind 56 wind turbines with a capacity of $10.3 \mathrm{MW}$.

A comparative analysis of the annual energy production of each wind farm was simulated to determine the optimal choice in this area. Two implementation configurations were chosen to ensure the proper execution of this work. The installation included all wind turbines of each type in a single row; the distance between two wind turbines must be four times the diameter of the turbine. Figure 13 illustrates wind farm 1 facing the directions of the prevailing winds.

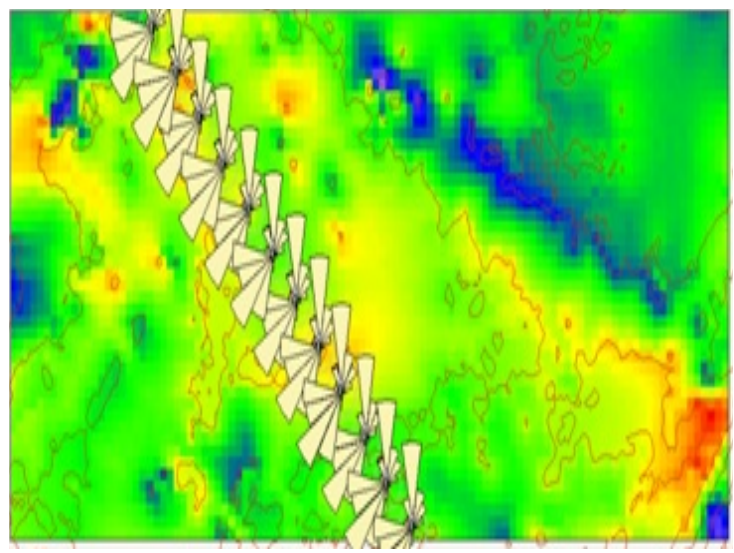

Fig.13 Dominant wind directions for one row

Secondly, the wind turbines were installed in two rows on the wind farm 2 (Figure 14). A distance of four times the diameter of the wind turbine and nine times the diameter distance between each line was defined.

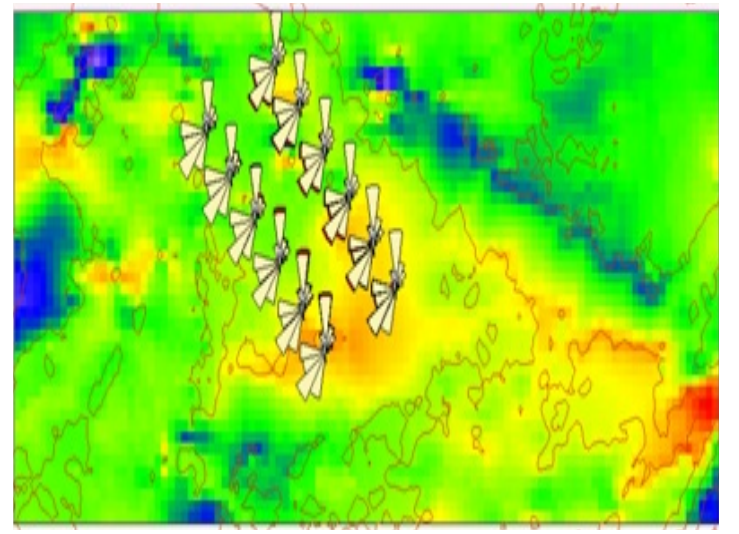

Fig.14 Dominant wind directions of the farm for two rows

\subsubsection{Results and interpretation}

The simulation of each technology was performed with WAsP software. A comparative study of several parameters such as annual energy production, losses by wake effect, mean annual wind speed and power density was conducted to optimize the overall efficiency of the wind farm, as shown in Tables 3 and 4.

The results summarized in Table 3 clearly show the advantage of wind farm PowerWind technology in terms of energy production, while the results presented in Table 4 (two rows) indicate a decrease in production parameters. However, the comparison of the two results demonstrates that the annual net energy produced, in the case of a single row aligned configuration, is distinctively higher than that of two rows, as well as the mean power density calculated by the Weibull function. 
Citation: Marih, S., Ghomri, L., and Bekkouche, B. (2020) Evaluation of the Wind Potential and Optimal Design of a Wind Farm in the Arzew Industrial Zone in Western Algeria. Int Journal of Renewable Energy Development, 9(2), 177-187, doi: 10.14710/ijred.9.2.177-187

$\mathrm{P}$ a g e | $\mathbf{1 8 4}$

Table 2.

Main characteristics of the selected turbines.

\begin{tabular}{lcccc} 
& Model & & \\
\cline { 2 - 5 } & Vestas V50 & NEG-Micon 750/44 & Nordex N50 & Power Wind 56 \\
\hline Rated capacity [KW] & 850 & 750 & 800 & 900 \\
Rotor diameter [m] & 52 & 44 & 50 & 56 \\
Hub height [m] & 55 & 50 & 50 & 59 \\
Cut in speed [m/s] & 4 & 4 & 4 & 15 \\
Rate speed [m/s] & 15 & 15 & 25 & 13 \\
Cut out speed [m/s] & 25 & 25 & & 25 \\
\hline
\end{tabular}

Table 3.

Result parameters produced by farms with one row

\begin{tabular}{|c|c|c|c|c|c|c|c|c|}
\hline \multirow{2}{*}{$\begin{array}{l}\text { Wind turbine } \\
\text { Parameter }\end{array}$} & \multicolumn{2}{|c|}{ VESTAS } & \multicolumn{2}{|c|}{ NEG MICON } & \multicolumn{2}{|c|}{ NORDEX } & \multicolumn{2}{|c|}{ POWER WIND } \\
\hline & Total & Average & Total & Average & Total & Average & Total & Average \\
\hline Net AEP [GWh] & 35,382 & 2,949 & 28,325 & 2,023 & 32,393 & 2,492 & 41,423 & 3,452 \\
\hline Gross AEP [GWh] & 35,718 & 2,976 & 28,532 & 2,038 & 32,855 & 2,527 & 41,823 & 3,485 \\
\hline Wake loss [\%] & 0.94 & - & 0.73 & - & 1.41 & - & 0.96 & - \\
\hline
\end{tabular}

Table 4.

Result parameters produced by farms with two rows

\begin{tabular}{lcccccccc} 
Wind turbine & \multicolumn{2}{c}{ VESTAS } & \multicolumn{2}{c}{ NEG MICON } & \multicolumn{2}{c}{ NORDEX } & \multicolumn{2}{c}{ POWER WIND } \\
\hline Parameter & Total & Average & Total & Average & Total & Average & Total & Average \\
Net AEP [GWh] & 34,906 & 2,909 & 27,594 & 1,971 & 31,849 & 2,450 & 40,925 & 3,410 \\
Gross AEP [GWh] & 35,873 & 2,989 & 28,125 & 2,009 & 33,071 & 2,544 & 42,069 & 3,503 \\
Wake loss [\%] & 2.69 & - & 1.89 & - & 3.7 & - & 2.72 & - \\
Mean speed [m/s] & - & 7.99 & - & 7.69 & - & 7.84 & - & 8.10 \\
Power density [W/m & - & 603 & - & 545 & - & 576 & - & 624
\end{tabular}

The mean wind farm speed values follow power density variations, which justifies the direct relationship between the two parameters. In addition, wind farm PowerWind technology retains the highest velocity value, approximately $8.1 \mathrm{~m} / \mathrm{s}$ in both implementation configurations. The other wind farm technologies have two different mean speed values for the two configurations. The same interpretation for wake effect losses obtained for a single row remains much lower than that of the two-row system. This concretizes the harmful effect of congestion created by a row on its neighbor.

Based on several simulations and Tables 3 and 4, it can be observed that the installation of single row wind farm turbines is more productive than the double row configuration, so that the site space is an essential parameter. In addition, to ensure good production, technology plays a major role depending on the characteristics of the site, in the case of the Arzew region, wind farm PowerWind technology is the most costeffective.

\section{Environmental and economic study}

HOMER ("HOMER - Hybrid Renewable and Distributed Generation System Design Software”.2018) software was used to evaluate the investment, maintenance and gas emissions costs of each technology related to a $3 \mathrm{MW}$ load. Arzew is a residential city and an industrial area. Figure 15 shows its load consumption profile. The consumption reached a maximum value of $3 \mathrm{MW}$ and a minimum value of $500 \mathrm{KW}$.
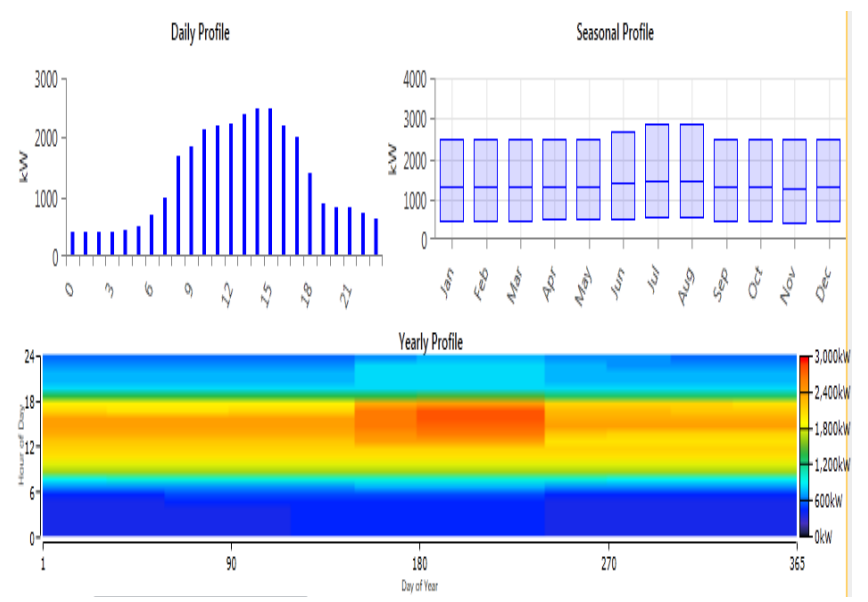

Fig.15 load profile

The operation of the installations is efficient for this load, as the production of the designed wind farm will be higher than the load demand of $3 \mathrm{MW}$, so the realization of this design will allow the entire industrial region to consume clean, non-polluting energy and improve the quality of the central network by injecting the surplus. Thus, at the national level, the creation of this wind farm allows the State to save a large part of the energy consumed locally. In terms of costs, Table 5 shows that wind farm PowerWind turbines are the cheapest. They produce the highest energy value. Table 6 shows that the wind farm PowerWind's cost of energy (COE ( $\$ / \mathrm{kWh})$ ) $\$ 0.068 / \mathrm{kWh}$ is the lowest compared to other models in our study. 
Table 5.

Net cost of a wind power system installation

\begin{tabular}{ccrrr}
\hline Wind Farm & Component (\$) & Capital (\$) & Maintenance (\$) & Total (\$) \\
\hline VESTAS & Grid & 0.00 & $8,560,907.18$ & $8,560,907.18$ \\
& Turbines & $5,760,000.00$ & $736,321.31$ & $6,496,321.31$ \\
NEG MICON & System & $5,760,000.00$ & $9,297,228.50$ & $15,067,228.50$ \\
& Grid & 0.00 & $9,686,391.93$ & $9,686,391.93$ \\
& Turbines & $4,550,000.00$ & $581,642.71$ & $5,131,642.71$ \\
NORDEX & System & $4,550,000.00$ & $10,268,034.64$ & $14,818,034.64$ \\
& Grid & 0.00 & $9,187,812.66$ & $9,187,812.66$ \\
& Turbines & $4,320,000.00$ & $552,240.99$ & $4,872,240.99$ \\
& System & $4,320,000.00$ & $9,740,053.64$ & $14,060,053.64$ \\
\hline POWER WIND & Grid & 0.00 & $7,872,412.84$ & $7,872,412.84$ \\
& Turbines & $2,100,000.00$ & $268,450.58$ & $2,368,450.48$ \\
& System & $2,100,000.00$ & $8,140,863.32$ & $10,240,863.32$ \\
\hline
\end{tabular}

Table 6 .

$\mathrm{COE}$ and Operating cost of a wind power system installation

\begin{tabular}{ccc}
\hline Wind Farm & Operating Cost (\$) & COE (\$) \\
\hline VESTAS & $727,291.70$ & 0.100 \\
NEG MICON & $803,231.60$ & 0.098 \\
NORDEX & $761,932.40$ & 0.093 \\
POWER WIND & $636,833.00$ & 0.068 \\
\hline
\end{tabular}

Regarding the study of Belabas et al (2015), the lowest value of electricity cost is obtained in Tiaret as $\$ 0.0342 / \mathrm{kW}$ $\mathrm{h}$ with the minimum specific cost of wind turbine using Vestas V80/2 MW model wind farm. Furthermore, the other costs of unit energy per $\mathrm{kWh}$, are obtained using AN Bonus $1000 \mathrm{~kW}$ turbine wind farm as $0.1723,0.0845,0.1290,0.1930$ and $\$ 0.2105 / \mathrm{kWh}$ in Miliana, Oran, Setif, Skikda, and Tlemcen respectively (Belabes et al., 2015). Also in study of Saheb Koussa et al, it was found that the minimum cost per $\mathrm{kWh}$ of electricity generated is about $\$ 0.10 / \mathrm{kWh}$ for Tamenrasset area, which represents the extreme southern region in Algeria, $\$ 0.03 / \mathrm{kWh}$ for Adrar and In salah ones, the south-western region, $\$ 0.06 / \mathrm{kWh}$ for Ghardaia, the mid-southern region, $\$ 0.07 / \mathrm{kWh}$ for Djelfa, the highland region and finally $\$ 0.03 / \mathrm{kWh}$ for Bouzareah, the coastal region. ( Koussa et al., 2016) a comparison between these studies and ours, we found that the cost of our installation is in a better situation, and gives a very acceptable value. Power plants generate greenhouse gas emissions, but wind turbine emissions remain low compared to most other electricity generation sectors, because their environmental impacts remain limited in the component manufacturing and installation phase of the construction site where fossil fuels are mainly used. These ratios were calculated with Homer software for all four installations. Table 7 summarizes the results, which show that wind farms built with PowerWind wind turbine model have fewer polluting gases than others.

\section{Conclusions}

An annual, monthly and seasonal analysis of wind data was carried out with the WAsP program to create a final wind mapping in the Arzew region. Two dominant wind directions were identified: Southwest (S-W) and North $(\mathrm{N})$. The studied site presented stable winds in a wide range from $3 \mathrm{~m} / \mathrm{s}$ to $6 \mathrm{~m} / \mathrm{s}$ with a maximum speed of $14 \mathrm{~m} / \mathrm{s}$. The variation in wind speed during the 10 -year study period was between $3.9 \mathrm{~m} / \mathrm{s}$ and $4.79 \mathrm{~m} / \mathrm{s}$. The Weibull parameter $\mathrm{k}$ varied from 1.38 to 2.12 and the power density was between $100 \mathrm{~W} / \mathrm{m}^{2}$ and $132 \mathrm{~W} / \mathrm{m}^{2}$.

A comparative study of four wind farm turbine technologies was conducted by simulating two different turbine placement configurations to find an adaptable and cost-effective technology for the site. 
Citation: Marih, S., Ghomri, L., and Bekkouche, B. (2020) Evaluation of the Wind Potential and Optimal Design of a Wind Farm in the Arzew Industrial Zone in Western Algeria. Int Journal of Renewable Energy Development, 9(2), 177-187, doi: 10.14710/ijred.9.2.177-187

$\mathrm{P}$ a g e | $\mathbf{1 8 6}$

Table 7.

Quantity of pollutant gases for the different wind energy conversion system

\begin{tabular}{cccc} 
Wind Farm & Quantity & Value & Units \\
\hline VESTAS & Carbon Dioxide & $4,232,451$ & $\mathrm{Kg} / \mathrm{yr}$ \\
& Sulfur Dioxide & 18,350 & $\mathrm{Kg} / \mathrm{yr}$ \\
& Nitrogen Oxides & 8,974 & $\mathrm{Kg} / \mathrm{yr}$ \\
\hline NEG MICON & Carbon Dioxide & $4,788,883$ & $\mathrm{Kg} / \mathrm{yr}$ \\
& Sulfur Dioxide & 20,762 & $\mathrm{Kg} / \mathrm{yr}$ \\
& Nitrogen Oxides & $\mathrm{Kg} / \mathrm{yr}$ \\
$\mathrm{Kg} / \mathrm{yr}$ & $\mathrm{Kg} / \mathrm{yr}$ \\
$\mathrm{Kg} / \mathrm{yr}$ & $\mathrm{Kg} / \mathrm{yr}$ \\
$\mathrm{Kg} / \mathrm{yr}$
\end{tabular}

The results showed that the single row structure produces more energy for all wind turbine models than for two rows. The model wind farm PowerWind had a $35 \%$ higher rate than other technologies for the same power, with 3,452 GWh of average annual energy produced, and $41,423 \mathrm{GWh}$ of total annual energy produced, for the configuration of a single row, and $3,410 \mathrm{GWh}, 40,925 \mathrm{GWh}$ respectively for the average annual and total energy for the configuration of two rows. The wind farm NEGMICON technology produced the minimum amount of energy, with an annual average of $2,492 \mathrm{GWh}$ and a total of $28,325 \mathrm{GWh}$ for the configuration of a single row. For the two-row configuration, the values of $1,971 \mathrm{GWh}$ and $27,594 \mathrm{GWh}$ of average and total energy produced respectively were recorded.

Finally, the reliability of this choice was confirmed by an economic and environmental study with a minimum cost of $\$ 0.068 / \mathrm{kWh}$ and a minimum value of $3,892,065 \mathrm{~kg} / \mathrm{year}$ of $\mathrm{CO} 2$, for the wind farm PowerWind, $\$ 0.1 / \mathrm{kWh}$ (the most expensive) for the wind farm VESTAS, while the wind farm NEGMICON technology was estimated at $\$ 0.098 / \mathrm{kWh}$, and a maximum $\mathrm{CO}_{2}$ for 4,788,883 $\mathrm{kg} /$ year and wind farm NEGMICON technology was estimated at $\$ 0.093 / \mathrm{kWh}$, and a value of $\mathrm{CO} 2$ for $4,542,389 \mathrm{~kg} /$ year. In the last step, the availability of the selected option was confirmed by an economic and environmental study with $\$ 0.068 / \mathrm{kWh}$ and $3,892,065 \mathrm{~kg} /$ year of $\mathrm{CO}_{2}$.

In conclusion, the Arzew region is a good site to create a wind farm to improve the quality of service of the western Algerian grid and to preserve the environment. Algeria has a 5,010 megawatt wind power production program; this wind farm and the Adrar wind farm will therefore contribute up to $0.4 \%$ to a national renewable energy project until 2030.

\section{References}

Abdeslame, D., Kasbadji Merzouk, N., Mekhtoub, S., Abbas, M., \& Dehmas, M. (2017). Estimation of power generation capacities of a wind farms installed in windy sites in Algerian high plateaus. Renewable Energy. https://doi.org/10.1016/j.renene.2016.10.075

Al Zohbi, G., Hendrick, P., \& Bouillard, P. (2015). Evaluation of the impact of wind farms on birds: The case study ofLebanon. Renewable Energy, 60, 682-689. https://doi.org/10.1016/j.renene.2015.02.052

Ang, J. B. (2007). CO2 emissions, energy consumption, and output in France. Energy Policy. https://doi.org/10.1016/j.enpol.2007.03.032

Belabes, B., Youcefi, A., Guerri, O., Djamai, M., \& Kaabeche, A (2015). Evaluation of wind energy potential and estimation of cost using wind energy turbines for electricity generation in north of Algeria. In Renewable and Sustainable Energy Reviews (Vol. 51, pp. 1245-1255). Elsevier Ltd. https://doi.org/10.1016/j.rser.2015.07.043

Benabdelkarim, B., \& Benatillah, A. (2016). Etude et simulation de l'effet des paramètres climatiques (température, poussière...) sur les modules solaires en couches minces en région saharien. Uraer.Cder.Dz, 1-5. http://uraer.cder.dz/sienr/sienr16/pvh/22_Article_B_BENAB DELKARIM_A22.pdf

Boudia, S. M., \& Guerri, O. (2015). Investigation of wind power potential at Oran, northwest of Algeria. Energy Conversion and https://doi.org/10.1016/j.enconman.2015.07.055

Edinger, R., \& Kaul, S. (2000). Humankind's detour toward sustainability: Past, present, and future of renewable energies and electric power generation. Renewable and Sustainable Energy Reviews. https://doi.org/10.1016/S13640321(99)00017-9

Emeksiz, C., \& Cetin, T. (2019). In case study: Investigation of tower shadow disturbance and wind shear variations effects on energy production, wind speed and power characteristics. Sustainable Energy Technologies and Assessments. https://doi.org/10.1016/j.seta.2019.07.004

Emeksiz, C., \& Demirci, B. (2019). The determination of offshore wind energy potential of Turkey by using novelty hybrid site selection method. Sustainable Energy Technologies and Assessments. https://doi.org/10.1016/j.seta.2019.100562

Georgopoulou, E., Sarafidis, Y., \& Diakoulaki, D. (1998). Design and implementation of a group DSS for sustaining renewable energies exploitation. European Journal of Operational Research. https://doi.org/10.1016/S0377-2217(98)00072-1

Halicioglu, F. (2009). An econometric study of CO2 emissions, energy consumption, income and foreign trade in Turkey. Energy Policy. https://doi.org/10.1016/j.enpol.2008.11.012

Himri, Y., Himri, S., \& Stambouli, A. B. (2010). Wind power resource in the south-western region of Algeria. In Renewable and Sustainable Energy Reviews. https://doi.org/10.1016/j.rser.2009.07.018

Himri, Y., Merzouk, M., Kasbadji Merzouk, N., \& Himri, S. (2020) Potential and economic feasibility of wind energy in south West region of Algeria. Sustainable Energy Technologies and Assessments. https://doi.org/10.1016/j.seta.2020.100643 
Home Page | Earth Resources Observation and Science (EROS) Center. Retrieved June 11, 2017, from https://eros.usgs.gov/

HOMER - Hybrid Renewable and Distributed Generation System Design Software. Retrieved July 2, 2018, from https://www.homerenergy.com/

Keyhani, A., Ghasemi-Varnamkhasti, M., Khanali, M., \& Abbaszadeh, R. (2010). An assessment of wind energy potential as a power generation source in the capital of Iran, Tehran. Energy. https://doi.org/10.1016/j.energy.2009.09.009

Khalid Saeed, M., Salam, A., Rehman, A. U., \& Abid Saeed, M. (2019). Comparison of six different methods of Weibull distribution for wind power assessment: A case study for a site in the Northern region of Pakistan. Sustainable Energy Technologies and Assessments. https://doi.org/10.1016/j.seta.2019.100541

Lashin, A., \& Shata, A. (2012). An analysis of wind power potential in Port Said, Egypt. In Renewable and Sustainable Energy Reviews (Vol. 16, Issue 9, pp. 6660-6667). Elsevier Ltd. https://doi.org/10.1016/j.rser.2012.08.012

Liu, Z., \& Yang, Y. (2009). A New Calculation Model of Wind Power. 2009 Asia-Pacific Power and Energy Engineering Conference, 1-3. https://doi.org/10.1109/APPEEC.2009.4918065

Louassa, S., Guerri, O., Merzouk, N. K., \& Merzouk, M. (2017). Wind resources estimation and performance evaluation of two wind farms in an Algerian arid zone. Proceedings of 2016 International Renewable and Sustainable Energy Conference, IRSEC 2016, 444-449. https://doi.org/10.1109/IRSEC.2016.7983943

Merzouk, N. K., \& Merzouk, M. (2012). Efficiency of three wind turbines installed on high plains region of Algeria. Procedia Engineering, 33, 450-457. https://doi.org/10.1016/j.proeng.2012.01.1224

Mohamed, B., Fadela, B., \& Mounir, K. (2015). Optimization of the Wind Turbines Location in Kaberten Wind Farm in Algeria. Energy https://doi.org/10.1016/j.egypro.2015.07.532
OUSSAMA, B. (2015). Evaluation of wind energy potential in the region southeast of the Algerian Sahara.

Ozturk, I., \& Acaravci, A. (2010). CO2 emissions, energy consumption and economic growth in Turkey. In Renewable and Sustainable Energy Reviews. https://doi.org/10.1016/j.rser.2010.07.005

Programme national de développement des énergies renouvelables (2015 - 2030) - Portail Algérien des Energies Renouvelables. (n.d.). Retrieved December 27, 2017, from http://portail.cder.dz/spip.php?article4446

Quan, P., \& Leephakpreeda, T. (2015). Assessment of wind energy potential for selecting wind turbines: An application to Thailand. Sustainable Energy Technologies and Assessments. https://doi.org/10.1016/j.seta.2015.05.002

Reiche, D., \& Bechberger, M. (2004). Policy differences in the promotion of renewable energies in the EU member states. Energy Policy. https://doi.org/10.1016/S0301-4215(02)003439

Saheb Koussa, D., Koussa, M., \& Hadji, S. (2016). Assessment of various WTG (wind turbine generators) production in different Algerian's climatic zones. Energy, 96, 449-460. https://doi.org/10.1016/j.energy.2015.12.072

Stambouli, A. B. (2011). Promotion of renewable energies in Algeria: Strategies and perspectives. In Renewable and Sustainable Energy Reviews. https://doi.org/10.1016/j.rser.2010.11.017

Wind energy industry-standard software - WAsP. (n.d.). Retrieved June 11, 2017, from http://www.wasp.dk/

Wright, A. (2010). Wind Turbine Control Systems. In Wind Turbine Technology: Fundamental Concepts in Wind Turbine Engineering, Second Edition (pp. 741-757). ASME. https://doi.org/10.1115/1.802601.ch14

Zhang, Z. X. (2007). China is moving away the pattern of "develop first and then treat the pollution." Energy Policy. https://doi.org/10.1016/j.enpol.2007.02.002 